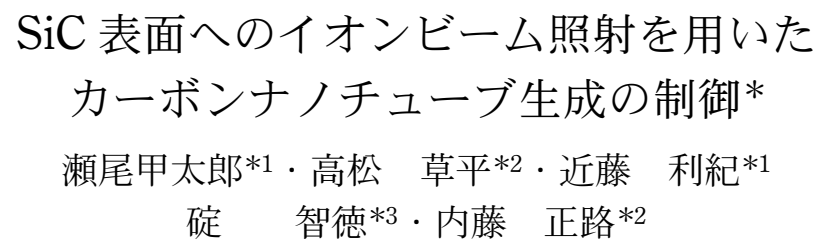

\title{
Growth Control of Carbon Nanotubes Using Ion-Beam Irradiation Effect in the SiC Surface Decomposition Method
}

\author{
Kotaro SEO*1, Sohei TAKAMATSU*2, Toshinori KONDO*1, \\ Tomonori IKARI*3 and Masamichi NAITOH*2 \\ ${ }^{* 1}$ Department of Electrical and Electronic Engineering, Kyushu Institute of Technology, \\ 1-1 Sensui, Tobata-ku, Kitakyushu-shi, Fukuoka 804-8550, Japan \\ ${ }^{* 2}$ Graduate School of Life Science and Systems Engineering, Kyushu Institute of Technology, \\ 2-4 Hibikino, Wakamatsu-ku, Kitakyushu-shi, Fukuoka 808-0196, Japan \\ *3Ube National College of Technology, 2-14-1 Tokiwadai, Ube-shi, Yamaguchi 755-8555, Japan
}

(Received November 19, 2013, Accepted February 12, 2014)

\begin{abstract}
We have investigated ion-beam irradiation effects on the growth of carbon nanotubes (CNTs) in the SiC surface decomposition method. A SiC $(000 \overline{1})$ surface was irradiated by $\mathrm{Ar}^{+}$ion with 1 or $5 \mathrm{keV}$ for $1 \mathrm{~h}$ and then annealed at $1700^{\circ} \mathrm{C}$ for $2 \mathrm{~h}$ at a pressure of $2 \times$ $10^{-2} \mathrm{~Pa}$. We found that the CNTs grown on the surface with $1 \mathrm{keV} \mathrm{Ar}{ }^{+}$ion irradiation are longer than CNTs grown without $\mathrm{Ar}^{+}$ion irradiation. In the case of $\mathrm{Ar}^{+}$ion irradiation at $5 \mathrm{keV}$, short CNTs are formed on the surface. These results indicate that damage to the $\mathrm{SiC}(000 \overline{1})$ surface affects the CNT formation in the $\mathrm{SiC}$ surface decomposition method.
\end{abstract}

\section{1. はじめに}

カーボンナノチューブ（CNT） は炭素原子から成るグラ フェンシートが円筒状に構成された物質で, 電気·熱伝導 性, 機械的強度, ガス吸蔵性などにおいて優れた特性を有し ており，様々な分野での応用が期待されている1-4).

CNTの生成方法は多々存在するが，本研究ではその内の 一つの生成方法である $\mathrm{SiC}$ 表面分解法に着目した． $\mathrm{SiC}$ 表面 分解法は真空中で $\mathrm{SiC}$ 単結晶を加熱するだけで触媒無しに CNT を生成する方法である ${ }^{5-8)}$ ，この方法では高配向，高密 度でジグザグ型の CNTを容易に生成することができるが， この方法により作製された CNT を更なる応用へと展開して いくためには，CNTの長さや直径などのサイズ制御や選択 成長技術などの知見を得る必要がある.

本研究では, 熱処理前の $\mathrm{SiC}$ 基板表面に $\mathrm{Ar}^{+}$イオンビー ムを照射することによる表面構造の変化が CNT 生成に与え る影響について, 透過型電子顕微鏡 $(\mathrm{TEM}), \mathrm{X}$ 線光電子分 光法 (XPS) 及びラマン分光法を用いて調べた.

\section{2. 実験方法}

$6 \mathrm{H}-\mathrm{SiC}(000 \overline{1})$ ウェハから $1 \times 7 \times 0.33 \mathrm{~mm}^{3}$ に切り出した 試料をエタノールと純水でそれぞれ 3 分間超音波洗浄し, フッ酸洗浄により酸化膜除去を行った. その後, $\mathrm{SiC}$ 試料に

* 平成25年11月26日 第54回真空に関する連合講演会で発表

*1 九州工業大学大学院工学研究院 (下804-8550 福岡県北九州市 戸畑区仙水町 1-1)

*2 九州工業大学大学院生命体工学研究科 (T808-0196 福岡県北 九州市若松区ひびきの 2-4)

*3 宇部工業高等専門学校（干755-8555 山口県宇部市常盤台 214-1)
$\mathrm{Ar}^{+}$イオンを照射（照射エネルギー：1 keV $\cdot 5 \mathrm{keV}$ ，照射 時間 : $1 \mathrm{~h}$, 照射量 : $4.5 \times 10^{15}$ atoms $/ \mathrm{cm}^{2}$, 照射角度 $45^{\circ}$ ) し, 高真空中 $\left(2.0 \times 10^{-2} \mathrm{~Pa}\right)$ で $1700^{\circ} \mathrm{C}$ (昇温レート : 100 $\left.{ }^{\circ} \mathrm{C} / \mathrm{min}\right), 2 \mathrm{~h}$ の熱処理により $\mathrm{CNT}$ 生成を行った。熱処理後 の試料は50 $\mu \mathrm{m}$ までダイヤモンドシートによる研磨を行い, 集束イオンビーム法を用いて厚さ $100 \mathrm{~nm}$ まで薄片化し, TEM 観察（加速電圧 : $200 \mathrm{kV}$ ) を行った.さらに, XPS ( $\mathrm{X}$ 線源 : $\mathrm{AlK} \alpha$, 波長 : $0.834 \mathrm{~nm}$ ，パスエネルギー：20 $\mathrm{eV}$, 検出角 : $\left.35^{\circ}\right)$ によりイオンビーム照射後の試料表面, ラマン分光法（励起源： $\mathrm{Ar}^{+}$, 励起波長 : $514.5 \mathrm{~nm}$ ) により 生成した CNTの結晶性について調べた.

\section{3. 実験結果及び考察}

Fig. 1(a)は，イオンビーム照射なしで熱処理を行った $\mathrm{SiC}$ 試料の断面 TEM 像である. Fig. 1(a)より， $\mathrm{SiC}$ 表面上 に約 $130 \mathrm{~nm}$ の長さのCNTが形成されたことがわかる。

Fig. 1(b)，（c）はそれぞれ $\mathrm{Ar}^{+}$イオンを照射エネルギー1 $\mathrm{keV}$ 及び $5 \mathrm{keV}$ で $\mathrm{SiC}$ 表面に照射した後に熱処理を行った 試料の断面 TEM 像である. Fig. 1(b)より $1 \mathrm{keV}$ で照射を 行った場合には $\mathrm{SiC}$ 表面上に約 $270 \mathrm{~nm}$ の長さの CNT が形 成され，Fig. 1(c)より $5 \mathrm{keV}$ で照射を行った場合には約70 $\mathrm{nm}$ の長さの CNT が形成されたことがわかる。これらの結 果は, 熱処理前の $\mathrm{SiC}$ 表面に特定のエネルギーの $\mathrm{Ar}^{+}$イオ ンビームを照射することにより CNT 生成を促進あるいは抑 制できることを示している.

$\mathrm{Ar}^{+}$イオンビーム照射による $\mathrm{SiC}$ 表面への影響を調べる ためにXPS 測定より $\mathrm{SiC}$ 表面の化学結合状態の分析を行っ た. Fig. 2 はそれぞれ $\mathrm{Ar}^{+}$イオンビーム照射なし, 照射工 ネルギー $1 \mathrm{keV}$ 及び $5 \mathrm{keV}$ で熱処理前の $\mathrm{SiC}$ 表面に照射し 


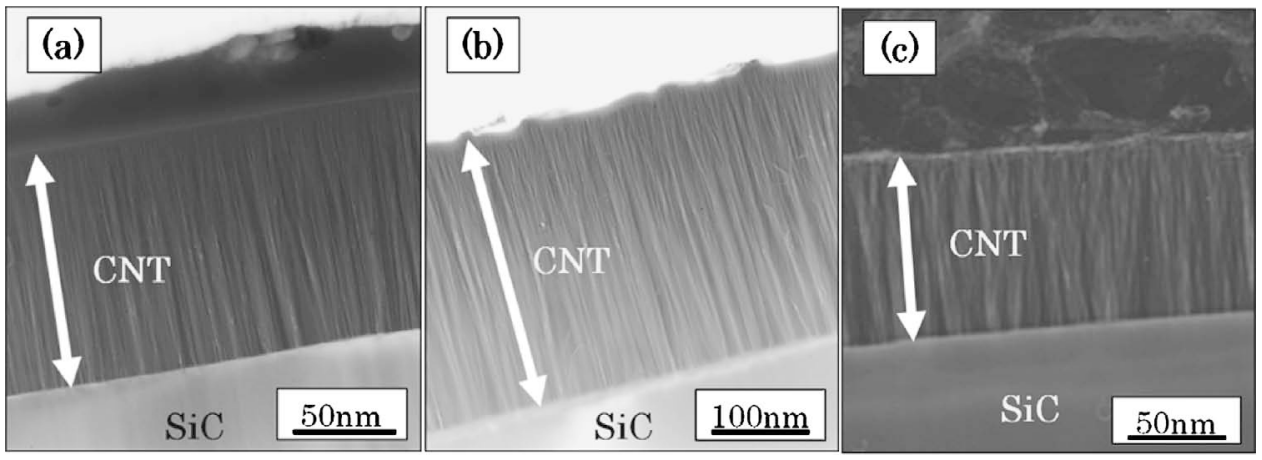

Fig. 1 Cross-sectional TEM images of the interface formed by annealing the $6 \mathrm{H}-\mathrm{SiC}(000 \overline{1})$ surface (a) without $\mathrm{Ar}^{+}$ion irradiation and with $\mathrm{Ar}^{+}$ion irradiation at (b) $1 \mathrm{keV}$ and (c) $5 \mathrm{keV}$.

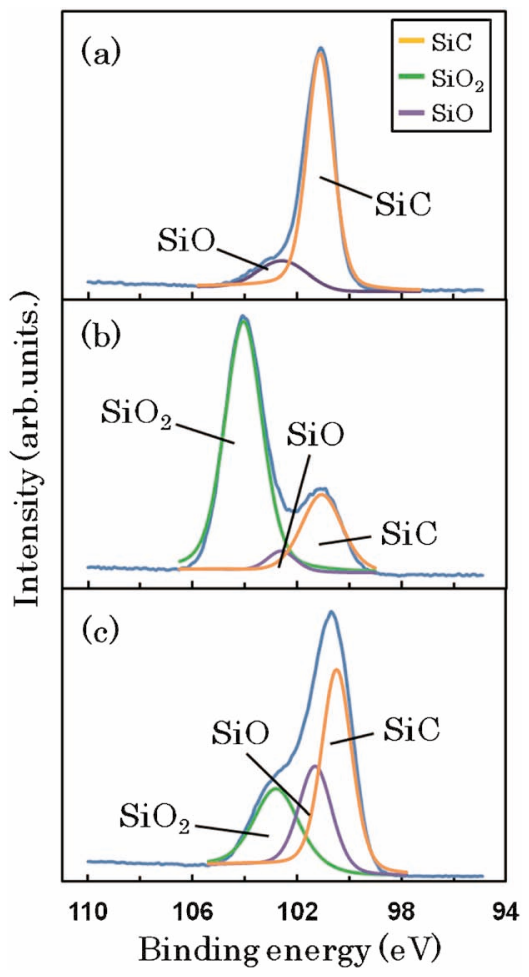

Fig. 2 Deconvoluted Si $2 p$ XPS spectra for $\operatorname{SiC}(000 \overline{1})$ surfaces (a) as received, with $\mathrm{Ar}^{+}$ion irradiation at (b) $1 \mathrm{keV}$ and (c) $5 \mathrm{keV}$.

た試料から測定した Si 2p スペクトルである.Fig. 2(b)， (c)より $\mathrm{Ar}^{+}$イオンビームを照射することで Si 酸化物 $\left(\mathrm{SiO}_{2}, \mathrm{SiO}\right)$ のピーク強度が増加していることがわかる. この原因として, $\mathrm{Ar}^{+}$イオンビーム照射により $\mathrm{SiC}$ 表面の $\mathrm{Si}$ 原子と C 原子の結合が切れ, $\mathrm{Ar}^{+}$イオンビーム照射後の 試料をXPS 測定のために別チャンバーに移送する際に大気 に曝したことで Si が酸化したことが挙げられる.

Fig. 3 に，照射エネルギー $1 \mathrm{keV}$ 及び $5 \mathrm{keV}$ 条件で $\mathrm{Ar}^{+}$イオンを $\mathrm{SiC}$ に照射した際に $\mathrm{SiC}$ 表面から深さ方向に 対する注入された $\mathrm{Ar}$ 原子の分布と照射損傷をシミュレーシ ョンソフト (SRIM 2013)9)により求めた結果を示す. 照射 損傷については，原子 1 個あたりの平均变位量 dpa（displacement per atom) で表されている. Fig. 3 より照射エネ ルギー $1 \mathrm{keV}$ 及び $5 \mathrm{keV}$ においては $\mathrm{Ar}$ 原子が平均で $1.8 \mathrm{~nm}$,
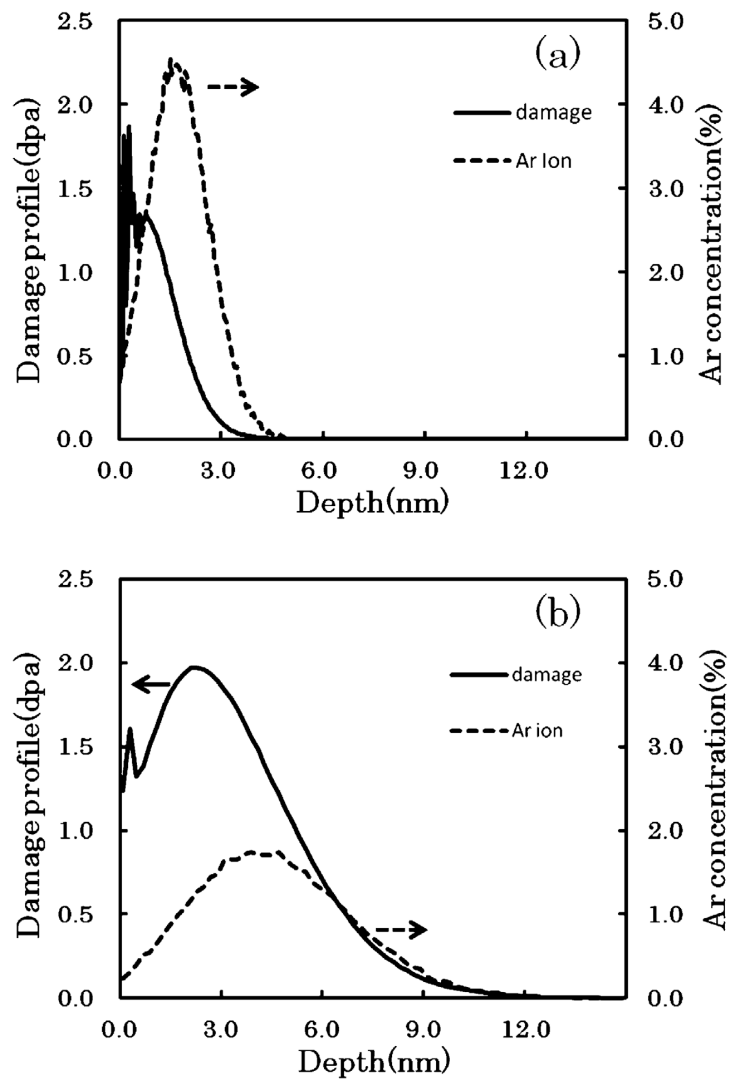

Fig. 3 The distributions of $\mathrm{Ar}$ atoms and damages of the $\mathrm{SiC}$ surface with $\mathrm{Ar}^{+}$ion irradiation at (a) $1 \mathrm{keV}$ and (b) $5 \mathrm{keV}$, calculated by SRIM 2013.

$4.6 \mathrm{~nm}$ 侵入し，損傷を与える範囲は表面から $3 \mathrm{~nm}, 9 \mathrm{~nm}$ 程度であることが予測できる.XPS の検出深さは通常数 nm 程度であることから，照射エネルギーが $1 \mathrm{keV}$ 及び $5 \mathrm{keV}$ のどちらの場合も, $\mathrm{Ar}^{+}$イオンビーム照射による損傷表面 を主に測定していると考えられる.よって $\mathrm{Ar}^{+}$イオンビー

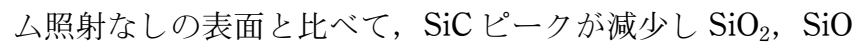
ピークが増加する．照射エネルギーが $5 \mathrm{keV}$ の場合, Fig. 3 (b) から $\mathrm{Ar}^{+}$イオンビーム照射による損傷は深さ $3 \mathrm{~nm} の$ と ころで最大になるので，最表面付近ではあまり損傷が大きく なく, 従って $\mathrm{SiC}$ 結合が多く残っていると考えられるので, $\mathrm{SiC}$ ピークの減少と $\mathrm{SiO}_{2}$ ピークの増大が抑えられている.

SRIM により Fig. 3(a)の実験条件でのC 及び Si のスパッ 
タリング率 (atoms/ion) を求めるとそれぞれ $1.30,2.19$ と 見積もることができ, $\mathrm{Si}$ が Cよりもスパッタリングされや すいことがわかる，そのため， $\mathrm{SiC}$ 表面が Cリッチになり， CNT 形成を促進する一因となっていると思われる.

照射エネルギー $5 \mathrm{keV}$ においては， $0.4 \mathrm{dpa}$ 程度でアモル ファス化が生じる10)ことを考慮すると, 約 $7.2 \mathrm{~nm}$ の厚さの アモルファス $\mathrm{SiC}$ が形成されると予想できる.

熱処理前の $\mathrm{SiC}$ 表面への $\mathrm{Ar}^{+}$イオンビーム照射が CNT の成長の促進及び抑制する原因として, Si と Cの結合の破 壊及び $\mathrm{Ar}^{+}$イオンが $\mathrm{SiC}$ 内部に侵入することで導入される 損傷の範囲が関係していることが考えられる. SiC 表面分解 法に颃いて, 次のような CNT 成長様式が提案されている. 初めに $\mathrm{SiC}$ 基板を加熱することで酸化反応が表面で起こり, $\mathrm{Si}$ 原子が $\mathrm{SiO}$ として脱離して残された $\mathrm{C}$ 原子が $\mathrm{CNT}$ の前 駆体であるカーボンナノキャップを形成する.さらに加熱す ることで, $\mathrm{SiC}$ の分解が継続され, $\mathrm{Si}$ 原子のみが蒸発し,

$\mathrm{SiC}$ 基板内部に向けて $\mathrm{CNT}$ が $\mathrm{SiC}$ 結晶中のジグザグのエッ ジを有する六員環の構造を利用してジグザグ型の CNT が成 長する ${ }^{8)}$.

照射エネルギー $1 \mathrm{keV}$ の $\mathrm{Ar}^{+}$イオンビームの照射により CNTの成長が促進した理由として，Figs. 2(b)，3(a)の結 果より， $\mathrm{SiC}$ 表面近傍に損傷が導入されることで $\mathrm{Si}$ と C の 結合が破壊され，熱処理時において $\mathrm{Si}$ の脱離が容易になる ことでカーボンナノキャップが形成しやすくなり，CNTの 成長が促進したと考えられる. また, 照射エネルギー $5 \mathrm{keV}$ の $\mathrm{Ar}^{+}$イオンビームを照射することで CNT の成長が抑制 された理由として，Fig. 3(b)より， $\mathrm{Ar}^{+}$イオンが $\mathrm{SiC}$ 表面 から内部に侵入することで損傷が $\mathrm{SiC}$ 表面だけでなく内部 にまで導入され, $\mathrm{SiC}$ 内部の結晶構造が乱されるアモルファ ス化が起こり，そして熱処理時に抢いて $\mathrm{SiC}$ の結晶構造が 乱れている状態が $\mathrm{SiC}$ の六員環の構造を利用して C 原子が CNT を形成していく成長過程を阻害するため, 成長が抑制 されたと考えられる.

Fig. 4 にそれぞれ $\mathrm{Ar}^{+}$イオンビーム照射なしで生成した $\mathrm{CNT}$, 照射エネルギー $1 \mathrm{keV}$ 及び $5 \mathrm{keV}$ の $\mathrm{Ar}^{+}$イオンビー ム照射後に生成した CNT のラマン分光法により測定したラ マンスペクトルを示す. $1350 \mathrm{~cm}^{-1}$ 付近の D バンドと 1600 $\mathrm{cm}^{-1}$ 付近の $\mathrm{G}$ バンドのピークの強度比 $(\mathrm{G} / \mathrm{D}$ 比）より生 成した CNTの結晶性の評価を行うと，イオンビーム照射な しで生成した CNT 及び照射エネルギー $5 \mathrm{keV}$ のイオンビー

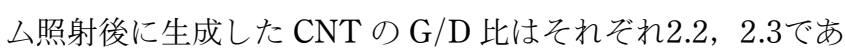
った。 それに対して照射エネルギー $1 \mathrm{keV} の \mathrm{Ar}^{+}$イオン ビーム照射後に生成した CNT の G/D 比は 4.4 と高い数值を 示して抢り，他二つと比較して結晶性のよい CNT が生成し ている可能性が高いことがわかった. 熱処理時において, 照

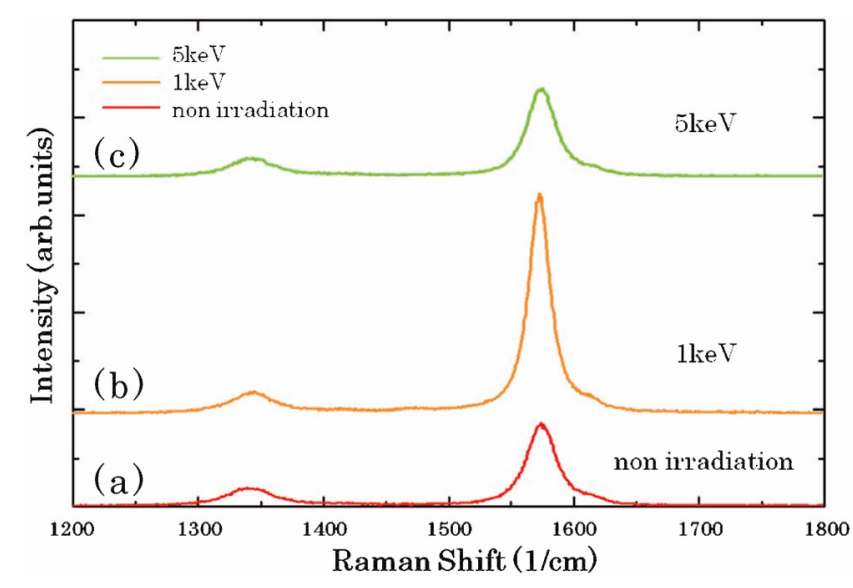

Fig. 4 Raman spectra obtained after annealing $6 \mathrm{H}-\mathrm{SiC}$ $(000 \overline{1})$ surfaces (a) without and with $\mathrm{Ar}^{+}$ion irradiation at (b) $1 \mathrm{keV}$ and (c) $5 \mathrm{keV}$.

射エネルギー $1 \mathrm{keV}$ の $\mathrm{Ar}^{+}$イオンビーム照射により $\mathrm{Si}$ が脱 離しやすくなっている状態が, 欠皕の少ない炭素六員環の形 成を促進していることが推察できる.

今後, イオンビームの種類, 照射量等を変化させたときの CNT 生成について, またイオンビームを照射した $\mathrm{SiC}$ 表面 の観察や表面損傷について調べる必要がある.

\section{4. まとめ}

熱処理前の $\mathrm{SiC}$ 表面に様々な条件で $\mathrm{Ar}^{+}$イオンビームを 照射することで，CNT 生成を促進及び抑制できることがわ かった．また，照射エネルギーを変化させることで結晶性の よいCNTを生成できる可能性が示唆された.

\section{〔文献〕}

1) H. J. Dai, J. H. Hafner, A. G. Rinzler, D. T. Colbert and R. E. Smalley: Nature, 384 (1996) 147.

2) W. A. de Heer, A. Châtelain and D. Ugarte: Science, 270 (1995) 1179.

3) J. Kong, N. R. Franklin, C. Zhou, M. G. Chapline, S. Peng, K. Cho and H. Dai: Science, 287 (2000) 622.

4) C. Liu, Y. Y. Fan, M. Liu, H. T. Cong, H. M. Cheng and M. S. Dresselhaus: Science, 286 (1999) 1127.

5) M. Kusunoki, M. Rokkaku and T. Suzuki: Appl. Phys. Lett., 71 (1997) 2620.

6) M. Kusunoki, J. Shibata, M. Rokkaku and T. Hirayama: Jpn. J. Appl. Phys., 37 (1998) L605.

7) M. Kusunoki, T. Suzuki, T. Hirayama, N. Shibata and K. Kaneko: Appl. Phys. Lett., 77 (2000) 531.

8) M. Kusunoki, T. Suzuki, C. Honjo, T. Hirayama and N. Shibata: Chem. Phys. Lett., 366 (2002) 458.

9) J. F. Ziegler, M. D. Ziegler and J. P. Biersak: Nucl. Instr. Meth. Phys. Res. Sect. B, 268 (2010) 1818.

10) W. J. Weber, L. M. Wang, N. Yu and N. J. Hess: Mater. Sci. Eng. A, 253 (1998) 62. 